\title{
A comprehensive autoantigen-ome of autoimmune liver diseases identified from dermatan sulfate affinity enrichment of liver tissue proteins
}

Wei Zhang ${ }^{1}$, Jung-hyun Rho ${ }^{2}$, Michael H. Roehrl $3^{3^{*}}$ and Julia Y. Wang ${ }^{4^{*}}$

\begin{abstract}
Background: Autoimmune diseases result from aberrant immune attacks by the body itself. It is mysterious how autoantigens, a large cohort of seemingly unconnected molecules expressed in different parts of the body, can induce similar autoimmune responses. We have previously found that dermatan sulfate (DS) can form complexes with molecules of apoptotic cells and stimulate autoreactive CD5+ B cells to produce autoantibodies. Hence, autoantigenic molecules share a unique biochemical property in their affinity to DS. This study sought to further test this uniform principle of autoantigenicity.

Results: Proteomes were extracted from freshly collected mouse livers. They were loaded onto columns packed with DS-Sepharose resins. Proteins were eluted with step gradients of increasing salt strength. Proteins that bound to DS with weak, moderate, or strong affinity were eluted with $0.4,0.6$, and $1.0 \mathrm{M} \mathrm{NaCl}$, respectively. After desalting, trypsin digestion, and gel electrophoresis, proteins were sequenced by mass spectrometry. To validate whether these proteins have been previously identified as autoantigens, an extensive literature search was conducted using the protein name or its alternative names as keywords. Of the 41 proteins identified from the strong DS-affinity fraction, 33 (80\%) were verified autoantigens. Of the 46 proteins with moderate DS-affinity, 27 (59\%) were verified autoantigens. Of the 125 proteins with weak DS-affinity, 44 (35\%) were known autoantigens. Strikingly, these autoantigens fell into the classical autoantibody categories of autoimmune liver diseases: ANA (anti-nuclear autoantibodies), SMA (anti-smooth muscle autoantibodies), AMA (anti-mitochondrial autoantibodies), and LKM (liver-kidney microsomal autoantigens).
\end{abstract}

Conclusions: This study of DS-affinity enrichment of liver proteins establishes a comprehensive autoantigen-ome for autoimmune liver diseases, yielding 104 verified and 108 potential autoantigens. The liver autoantigen-ome sheds light on the molecular origins of autoimmune liver diseases and further supports the notion of a unifying biochemical principle of autoantigenicity.

Keywords: Autoantigen, Autoantibody, Autoimmune liver disease, Hepatitis

\footnotetext{
* Correspondence: roehrlm@mskcc.org; julia@curandis.com

${ }^{3}$ Department of Pathology, Memorial Sloan Kettering Cancer Center, New

York, USA

${ }^{4}$ Curandis, New York, USA

Full list of author information is available at the end of the article
}

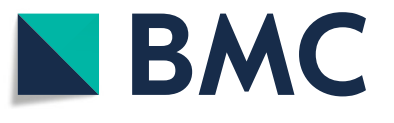

(c) The Author(s). 2019 Open Access This article is distributed under the terms of the Creative Commons Attribution 4.0 International License (http://creativecommons.org/licenses/by/4.0/), which permits unrestricted use, distribution, and reproduction in any medium, provided you give appropriate credit to the original author(s) and the source, provide a link to the Creative Commons license, and indicate if changes were made. The Creative Commons Public Domain Dedication waiver (http://creativecommons.org/publicdomain/zero/1.0/) applies to the data made available in this article, unless otherwise stated. 


\section{Background}

The etiology of autoimmune diseases in general has remained a biomedical mystery. It is not clear how and why some molecules or tissue components of the body become a self-target of the immune defense system, whereas most do not. In previous studies, we demonstrated that certain molecules from dying cells have affinity to dermatan sulfate (DS), and that these molecules can form macromolecular complexes with DS to costimulate autoreactive CD5+ B cells to secrete autoantibodies [1]. Furthermore, we demonstrated that molecules with affinity to DS have a high propensity to be autoantigens (autoAg) [2]. We proposed a uniform principle of autoantigenicity that explains how a vast variety of seemingly unrelated molecules can become autoantigenic by means of a shared biochemical property. In this study, we sought to test this principle and to define the repertoire of possible autoantigens, i.e., the autoantigen-ome, in autoimmune liver diseases.

Autoimmune diseases of the liver occur when the body's own immune system attacks the liver [3-5]. These diseases have different clinical patterns with regard to degree of severity and clinical course, but they all share one important feature, i.e., the liver being the target of an aberrant autoimmune attack by autoantibodies and/or autoreactive cells. Autoimmune liver diseases are typically chronic conditions, and patients may experience persistent or recurrent autoimmune insults to the liver, often without overt symptoms. As the autoimmune attack persists, liver tissue scars and leads to hepatic fibrosis; and as fibrosis progresses to cirrhosis, liver function is compromised. Ultimately, end-stage liver disease and liver failure may ensue, requiring organ transplantation.

Among autoimmune diseases of the liver, autoimmune hepatitis (AIH) [3], primary biliary cirrhosis (PBC) [4], and primary sclerosing cholangitis (PSC) [5] are the most prominent. In $\mathrm{AIH}$, the immune system attacks the hepatocytes and causes chronic inflammation of the liver. About $70 \%$ of AIH patients are female. In PBC, the autoimmune reaction is directed at small biliary ducts inside the liver. In PSC, autoimmunity targets the larger extrahepatic bile ducts. Characteristic morphological patterns are chronic inflammation and a hepatic pattern of injury with prominent plasma cells in AIH, destruction of small intrahepatic bile ducts and canals of Hering in $\mathrm{PBC}$, and periductal fibrosis and inflammation of the larger bile ducts, often along with inflammatory bowel disease, in PSC. Although most liver autoimmune diseases fall into these three categories, overlaps and other syndromes also occur.

Autoimmune liver diseases are typically associated with several classes of autoantibodies, including ANA, AMA, anti-SMA/anti-F-actin, anti-LKM, and others [6, 7]. For $\mathrm{AIH}$ and $\mathrm{PBC}$, testing for liver-related autoantibodies is a prerequisite for diagnosis. For PSC, autoantibodies are frequently present but their diagnostic value has not been established. When diagnosed at an early stage, autoimmune hepatitis can be controlled by daily doses of steroids and other medicines that suppress inflammation. However, these treatments only suppress or slow down the overactive immune system, but cannot cure the disease. Understanding the molecular origins of autoimmune liver diseases is therefore crucial to finding more effective therapies.

\section{Methods}

\section{DS-Sepharose resin synthesis}

DS-Sepharose resins were prepared by coupling dermatan sulfate (DS; Sigma-Aldrich) to EAH Sepharose 4B resins (GE Healthcare). Sepharose resins $(20 \mathrm{ml})$ were washed with distilled water and $0.5 \mathrm{M} \mathrm{NaCl}$ and then mixed with $100 \mathrm{mg}$ of DS dissolved in $10 \mathrm{ml}$ of $0.1 \mathrm{M}$ MES buffer (pH 5.0). N-ethyl-N-(3-dimethylaminopropyl) carbodiimide hydrochloride (Sigma-Aldrich) was added to a final concentration of $0.1 \mathrm{M}$. The reaction proceeded at $25^{\circ} \mathrm{C}$ for $24 \mathrm{~h}$ with end-over-end rotation. After the first $60 \mathrm{~min}$, the $\mathrm{pH}$ of the reaction mixture was readjusted to 5.0. After the coupling, the resins were washed three times, each time with a low $\mathrm{pH}$ buffer $(0.1$ $\mathrm{M}$ acetate, $0.5 \mathrm{M} \mathrm{NaCl}, \mathrm{pH} 5.0$ ) and a high $\mathrm{pH}$ buffer (0.1 M Tris, $0.5 \mathrm{M} \mathrm{NaCl}, \mathrm{pH} 8.0)$. The washed DSSepharose resins were suspended in $10 \mathrm{mM}$ phosphate buffer (pH 7.4) and packed into a C16/20 column (GE Healthcare). The column was equilibrated with $10 \mathrm{mM}$ phosphate buffer before use.

\section{Mouse liver protein extraction}

Livers were obtained from 5-month-old BALB/cJ female mice (Jackson Laboratory, Bar Harbor, Maine). The mouse tissue use was approved by the Institutional Animal Care and Use Committee (IACUC) of Brigham and Women's Hospital (Boston, MA). All animal care was provided according to institutional, local, state, and federal regulations at the Brigham and Women's Hospital research animal facility. A total of 20 mice were killed with $\mathrm{CO}_{2}$, their blood was removed through heart puncture, and their livers were collected immediately. Livers were cleaned by rinsing with phosphate buffered saline (PBS, pH 7.2) twice and then stored at $4{ }^{\circ} \mathrm{C}$ for $1 \mathrm{~h},-20^{\circ} \mathrm{C}$ for $2 \mathrm{~h}$, and then $-80^{\circ} \mathrm{C}$ until further processing. Thawed livers were cut to small pieces and pressed through a cell strainer (Fisher Scientific). To remove red blood cells, the liver tissue was mixed with $10 \mathrm{ml}$ of RBC (red blood cell) lysis buffer for $10 \mathrm{~s}$. After centrifugation for $5 \mathrm{~min}$, the supernatant was discarded. The liver tissue was mixed with $40 \mathrm{ml}$ of RIPA lysis buffer (Sigma-Aldrich) and 4 tablets of protease inhibitor (cOmplete protease inhibitor cocktail, Sigma-Aldrich). The tissue mixture was sonicated for $10 \mathrm{~min}$ or until all tissue pieces appeared dissolved. 
The mixture was centrifuged at $13,300 \mathrm{rpm}$ for $20 \mathrm{~min}$, and the supernatant that contains total soluble liver proteins was collected. Protein concentration was measured by the RC DC protein assay (Bio-Rad).

\section{DS-affinity fractionation}

Pilot affinity fractionations were performed in small centrifuge tubes. Aliquots of $2 \mathrm{ml}$ resin were centrifuged to remove the storage buffer, and $0.5 \mathrm{ml}$ of extracted liver proteins was added. The tube was mixed by rotating end-over-end at room temperature for $1 \mathrm{~h}$ to allow sufficient binding of proteins to DS-resin. The resin slush was centrifuged, and the supernatant containing unbound proteins was removed. The resins were washed 4 times with $1 \mathrm{ml}$ of $0.2 \mathrm{M} \mathrm{NaCl}$ in $10 \mathrm{mM}$ phosphate buffer to further remove unbound or poorly bound proteins. Proteins bound to DS with weak affinity were released from the resins by $0.4 \mathrm{M} \mathrm{NaCl}$ in PBS by rotating end-over-end at room temperature for $30 \mathrm{~min}$, and the supernatant containing weak-binding proteins was recovered by centrifugation. The high-affinity proteins still bound to DS-resin were obtained by boiling the resins with $0.2 \mathrm{ml}$ of SDS-PAGE sample buffer. Proteins in each fraction were assessed by 1D gel electrophoresis.

After the pilot assessment, fractionation of larger quantities of liver proteins was carried out by FPLC using a Biologic Duo-Flow System (Bio-Rad). Liver proteins were loaded into the DS-Sepharose column in $10 \mathrm{mM}$ phosphate buffer at a rate of $1 \mathrm{~mL} / \mathrm{min}$. The column was washed with $20 \mathrm{~mL}$ of buffer A to remove unbound proteins. Proteins bound to DS resins with weak-to-strong affinity were eluted with a step-gradient of $0.2 \mathrm{M}, 0.4 \mathrm{M}, 0.6$ $\mathrm{M}$, and $1.0 \mathrm{M} \mathrm{NaCl}$ in $10 \mathrm{mM}$ phosphate buffer, with each step being $40 \mathrm{ml}$. Elution was monitored by UV and conductivity detectors. All bound fractions were collected. Fractions were concentrated and desalted in Vivaspin centrifugal concentrators (MWCO $10 \mathrm{kDa}$, Sigma-Aldrich). Concentrated proteins were reconstituted in $10 \mathrm{mM}$ phosphate buffer for further analysis.

\section{Protein sequencing by mass spectrometry}

Fractionated proteins with different affinities to DS were separated on 1D SDS PAGE in 4-12\% NuPAGE Novex Bis-Tris gels (Invitrogen). Based on protein band intensity, the protein lane containing proteins eluting at 0.4 $\mathrm{M} \mathrm{NaCl}$ was cut into 3 sections, containing top, middle, and bottom bands. The lanes containing proteins eluting at $0.6 \mathrm{M}$ and $1.0 \mathrm{M} \mathrm{NaCl}$ were each cut into 2 sections, containing top and bottom bands, respectively. Gel sections were transferred into $1-\mathrm{ml}$ tubes, cut into tiny pieces, dehydrated with acetonitrile, and then dried in a speed-vac. Proteins in gel pieces were then rehydrated in $50 \mathrm{mM} \mathrm{NH}{ }_{4} \mathrm{HCO}_{3}$ and digested with $12.5 \mathrm{ng} / \mu \mathrm{l}$ modified sequencing-grade trypsin (Promega) at $4{ }^{\circ} \mathrm{C}$ overnight.
Mass spectrometric sequencing was performed at the Taplin Biological Mass Spectrometry Facility (Harvard Medical School, Boston, USA). Tryptic peptides were separated on a nano-scale C18 HPLC capillary column and analyzed after electrospray ionization in an LTQ linear ion-trap mass spectrometer (Thermo Scientific). Peptide sequences and protein identities were assigned by matching protein or translated nucleotide databases with the measured fragmentation pattern using Sequest software. Peptides were required to be fully tryptic peptides with XCorr values of at least 1.5 (+ 1 ion), 1.5 (+2 ion), or 3.0 (+ 3 ion). All data were manually inspected. Only proteins with at least 2 peptide matches were considered confidently identified.

\section{Results}

\section{Fractionation of liver proteins by DS-affinity}

Proteins extracted from mouse livers were separated into 4 fractions according to their strength of binding to DS: no-, weak-, medium-, and strong-affinity. This was carried out by loading the liver proteins onto DS-Sepharose columns to allow binding to take place. Proteins that did not bind to DS resins were washed off the column with the $10 \mathrm{mM}$ phosphate loading buffer, followed by washing with $0.2 \mathrm{M} \mathrm{NaCl}$ and $10 \mathrm{mM}$ phosphate buffer. Afterwards, proteins that had remained bound to DS were sequentially eluted from the column with $0.4 \mathrm{M}, 0.6 \mathrm{M}$, and $1.0 \mathrm{M} \mathrm{NaCl}$, designating these as weak-, medium-, and strong-affinity fractions, respectively. Elution was monitored for presence of proteins, and individual chromatographic fractions containing proteins at each of the salt strengths were pooled, desalted, and concentrated. Protein content and protein size distribution of the fractions were assessed with 1D SDS PAGE gels.

The majority of liver tissue proteins not binding to DS were observed in the flow-through, and non-specific binding proteins were further washed with $0.2 \mathrm{M} \mathrm{NaCl}$. As the elution proceeded, the amount of proteins eluting at increasing ionic strength became smaller and smaller. Proteins eluting last off the column with $1.0 \mathrm{M} \mathrm{NaCl}$ had the highest affinity to DS but were also the relatively least abundant. The flow-through and $0.2 \mathrm{M} \mathrm{NaCl}$ washed proteins were not further analyzed. Proteins eluting at $0.4 \mathrm{M}, 0.6 \mathrm{M}$, and $1.0 \mathrm{M}$ salt were sequenced by LC-MS/MS, yielding 168, 68 , and 41 identified protein entities, respectively. Some of the proteins were redundantly identified in 2 or 3 fractions and, when redundancies were excluded, the number of different uniquely identified proteins in the $0.4 \mathrm{M}, 0.6 \mathrm{M}$, or $1.0 \mathrm{M}$ fraction was found to be 125,46 , and 41 , respectively.

\section{Proteins with strong DS-affinity eluting at $1.0 \mathrm{M}$ ionic strength}

Proteins eluting off the DS-Sepharose column at $1.0 \mathrm{M}$ $\mathrm{NaCl}$ were classified as having strong DS-affinity. From 
the $1.0 \mathrm{M}$ elution, 41 proteins were identified by MS sequencing (Table 1). A literature search revealed that at least $33(80.5 \%)$ of these have previously been identified as autoantigens for autoantibodies. Furthermore, these autoantigens were not randomly distributed in functional attribution but fell nicely into 5 classical categories of autoantibodies in autoimmune liver diseases: ANA (antinuclear autoantibodies), SMA (smooth muscle autoantibodies), AMA (anti-mitochondrial autoantibodies), LKM (liver-kidney microsomal autoantigens), and peroxisome (Table 1).

Among the 41 proteins identified, 16 belong to the ANA family. They include 6 histones, 4 small nuclear ribonucleoproteins, 4 ribosomal proteins, and 2 others (polyadenylatebinding protein and barrier-to-autointegration factor). All of them are established ANA autoantigens (see references in Table 1). There are 5 proteins belonging to the SMA family, including spectrin alpha chain, myosin-9, myosin light chain, and lamin-A. All of them are known targets of autoantibodies (see references in Table 1). Among the AMA autoantigens, 7 were identified, with 4 having been verified as autoantigens, including Hspa5, Hspa9, glutamate dehydrogenase (Glud1), and apoptosis-inducing factor 1 (Aifm1). Autoantibodies to heat shock proteins (HSP) are widely found in autoimmune diseases as well as in numerous other diseases. Autoantibodies to HSP have been found in the circulation of various cancer patients, and are proposed as diagnostic and prognostic markers for various cancers such as breast cancer [40]. Autoantibodies to Glud1 have not been reported in humans but in mice and calves [27, 28]. Autoantibodies to Cpt2, Cps1, and Chdh could not be found in published reports. They could well represent autoantigens that have yet to be validated.

Autoantibodies to microsomal LKM antigens are associated with type 2 autoimmune hepatitis. Among proteins with high DS-affinity, 8 microsomal proteins were identified, including 3 of the UDG-glucuronosyltransferase family, 2 cytochromes, and 3 enzymes. Six of them (Ugtla9, Ugt2b5, UgtCyb5, Cyb5, Pdia3, and Ces3) are known bona fide autoantigens (Table 1). Autoantibodies to Cox6c and Ass1 have not yet been described in literature. There are 5 proteins associated with the peroxisome in the $1.0 \mathrm{M}$ elution fraction. Catalase and dipeptidyl peptidase (CD26, Dpp4) are reported autoantigens (Table 1). Autoantibodies to Acsl1, Uox, and Decr2 have not yet been reported.

\section{Proteins with moderate DS-affinity eluting at $0.6 \mathrm{M}$ ionic strength}

From fractions eluting at $0.6 \mathrm{M}$ salt from DS-affinity columns, 68 proteins were identified by MS, but 22 of them were also present in the $1.0 \mathrm{M}$ fraction. Therefore, 46 unique proteins were found (Table 2). Similarly to those with strong DS-affinity as described above, these proteins fell nicely into 5 categories of well-known autoantibodies: ANA, SMA, AMA, LKM, and peroxisome.

There are 15 proteins belonging to the ANA family, including 5 histones and 5 ribosomal proteins (Table 2). Aside from these, other interesting autoantigens were identified. DNA topisomerase 1, the classical Scl-70 autoantigen, was identified [45]. Casein kinase II was also identified [17]. Dxh9 (ATP-dependent RNA helicase and DNA helicase II) may resemble the classical $\mathrm{Ku}$ antigen [44]. Prpf8, a pre-mRNA-processing-splicing factor, has not been reported as an autoantigen.

There are 4 proteins belonging to the SMA family. Aside from 3 isoforms of lamin, autoantigen Hspg2 (basement membrane-specific heparan sulfate proteoglycan core protein) was found in the $0.6 \mathrm{M}$ elution. Among the 12 proteins in the AMA family, autoantibodies to 6 have been reported, including Bckdha, Suox, Hspa1l, Hmgcs2, Uqcrc1, and Hspa8. Although autoantibodies to $\mathrm{C} 1 \mathrm{q}$ have been widely studied, anti-C1qbp (complement $\mathrm{C} 1 \mathrm{q}$ subunit binding protein) has not yet been reported. Ssbp1, Hadha, Scl25a5, or Decr1 were not found in the literature as autoantigens.

From the $0.6 \mathrm{M}$ elution, all 6 proteins identified in the LKM family are reported autoantigens (see references in Table 2). The classical cytochrome P450 antigens including LKM1 were identified. Other autoantigens identified are UDP-glucuronosyltransferase 1, Arg1, and Ganab. In addition to the above classical categories of autoantigens, 6 proteins identified in the $0.6 \mathrm{M}$ elution are miscellaneous. Except for Rdh7 being a reported autoantigen, Hsd11b1, Ddost, Slc27a5, Rpn1, and Hsd17b6 autoantibodies remain to be characterized.

\section{Proteins with weak DS-affinity eluting at $0.4 \mathrm{M}$ ionic strength}

From fractions eluting at $0.4 \mathrm{M}$ salt, 168 proteins were initially identified. Among these, 18 were also found in both $0.6 \mathrm{M}$ and $1.0 \mathrm{M}$ elution, including $\mathrm{H} 2 \mathrm{bj}, \mathrm{H} 2 \mathrm{afj}$, H2afy, Snrpb, Myh9, Lmna, Hspa9, Hspa5, Cps1, Cpt2, Glud1, Ugt2b5, Pdia3, Ass1, Acsl1, Cat, Uox, and Aif. Among the rest, 3 (Sm D2, Spna2, and Ces) were found also in the $1.0 \mathrm{M}$ elution but in not $0.6 \mathrm{M}$ elution, and 22 proteins were found also in the $0.6 \mathrm{M}$ but not in the $1.0 \mathrm{M}$ elution. After excluding these redundancies, 125 proteins were found only in the $0.4 \mathrm{M}$ elution (Table 3).

As shown in Table 3, these 125 proteins fell naturally into 8 categories: ANA (10 proteins), SMA (15 proteins), AMA (35 proteins), LKM (10 proteins), peroxisome (6 proteins), apoptosis (4 proteins), proteasome (11 proteins), and miscellaneous (34 proteins).

The ANA autoantigens with weak DS-affinity are primarily isoforms of splicing factors and small nuclear ribonucleoproteins. Although autoantibodies to splicing factors have been reported [63], the exact isoforms 
Table 1 Liver proteins with strong DS-affinity

\begin{tabular}{|c|c|c|c|c|}
\hline \multicolumn{3}{|l|}{ a } & \multirow{2}{*}{$\begin{array}{l}\text { ANA (antinuclear autoantigens) } \\
\text { Histone } \mathrm{H} 4\end{array}$} & \multirow{2}{*}{$\begin{array}{l}\text { Ref. } \\
{[8]}\end{array}$} \\
\hline 10 & IPI00329998.3 & $\mathrm{H} 4$ & & \\
\hline 6 & IPI00114642.4 & Hist1h2bj & Histone $\mathrm{H} 2 \mathrm{~B}$ type $1-\mathrm{F} / \mathrm{J} / \mathrm{L}$ & [9] \\
\hline 5 & IPI00153400.2 & H2afj & Histone H2A.J & [9] \\
\hline 5 & IPI00111957.3 & Hist1h2ba & Histone H2B type 1-A & [9] \\
\hline 4 & IPI00137852.5 & H2afy & Core histone macro-H2A.1 & {$[10]$} \\
\hline 2 & IPI00404590.1 & $\mathrm{H} 1 \mathrm{fO}$ & Histone $\mathrm{H} 1.0$ & [11] \\
\hline 3 & IPI00119220.1 & Snrpd2 & Small nuclear ribonucleoprotein Sm D2 & [12] \\
\hline 2 & IPI00114052.1 & Snrpb & Small nuclear ribonucleoprotein-associated protein B & [13] \\
\hline 2 & IPI00122350.4 & Snrpa & U1 small nuclear ribonucleoprotein A & [14] \\
\hline 2 & IPI00133955.1 & Snrpe & Small nuclear ribonucleoprotein $\mathrm{E}$ & [15] \\
\hline 3 & IPI00131988.1 & Mrpl49 & 395 ribosomal protein $L 49$, mitochondria & [16] \\
\hline 3 & IPI00311236.1 & Rpl7 & 605 ribosomal protein $\mathrm{L} 7$ & [17] \\
\hline 2 & IPI00122421.5 & Rpl27 & 605 ribosomal protein $L 27$ & [18] \\
\hline 2 & IPI00222549.6 & Rpl30 & 605 ribosomal protein $L 30$ & [16] \\
\hline 3 & IPI00124287.1 & Pabpc1 & Polyadenylate-binding protein & [19] \\
\hline \multirow[t]{2}{*}{2} & IPI00119959.1 & Banf1 & Barrier-to-autointegration factor & [20] \\
\hline & & & SMA (anti-smooth muscle autoantigens) / Cytoskeleton & \\
\hline 6 & IPI00753793.2 & Spna2 & Isoform 2 of Spectrin alpha chain & [21] \\
\hline 5 & IPI00123181.4 & Myh9 & Myosin-9 & [22] \\
\hline 2 & IPI00109044.8 & G15Rik & Myosin light chain, regulatory B-like & [23] \\
\hline 2 & IPI00354819.5 & Myl6 & Isoform Smooth muscle of Myosin light chain 6 & [24] \\
\hline \multirow[t]{2}{*}{2} & IPI00230435.1 & Lmna & Isoform C2 of Lamin-A & [25] \\
\hline & & & AMA (anti-mitochondrial autoantigens) & \\
\hline 13 & IPI00319992.1 & Hspa5 & 78 kDa glucose-regulated protein (Grp78) & [26] \\
\hline 13 & IPI00114209.1 & Glud1 & Glutamate dehydrogenase 1, mitochondria & {$[27,28]$} \\
\hline 11 & IPI00131424.3 & Cpt2 & Carnitine O-palmitoyltransferase 2, mitochondria & \\
\hline 6 & IPI00133903.1 & Hspa9 & Stress-70 protein, mitochondria (Grp75) & [29] \\
\hline 3 & IPI00111908.8 & Cps1 & Carbamoyl-phosphate synthase [ammonia], mitochondria & \\
\hline 3 & IPI00273146.1 & Chdh & Choline dehydrogenase, mitochondria & \\
\hline \multirow[t]{2}{*}{2} & IPI00129577.1 & Aifm1 & Apoptosis-inducing factor 1 (Aif, Pdcd8, programmed cell death protein 8), mitochondria & [30] \\
\hline & & & LKM (liver-kidney microsomal autoantigens) & \\
\hline 3 & IPI00111936.1 & Ugt1a9 & UDP-glucuronosyltransferase 1-9 (bilirubin-specific) & [31] \\
\hline 3 & IPI00112322.2 & Ugt2b5 & UDP glucuronosyltransferase 2 family, polypeptide B5 & [32] \\
\hline 2 & IPI00230113.5 & Cyb5 & Microsomal cytochrome b5 & [33] \\
\hline 2 & IPI00131771.3 & Cox6c & Cytochrome c oxidase subunit $6 \mathrm{c}$ & \\
\hline 2 & IPI00169666.3 & Ugt2b34 & UDP glucuronosyltransferase 2 family, polypeptide B3 & [32] \\
\hline 2 & IPI00230108.6 & Pdia3 & Protein disulfide-isomerase A & [34] \\
\hline 2 & IPI00134746.5 & Ass1 & Argininosuccinate synthase & \\
\hline \multirow[t]{2}{*}{2} & IPI00387289.3 & Ces3 & Carboxylesterase & [35] \\
\hline & & & Peroxisomal proteins & \\
\hline 3 & IPI00112549.1 & Acsl1 & Long-chain-fatty-acid-CoA ligase & \\
\hline 2 & IPI00312058.5 & Cat & Catalase & {$[36,37]$} \\
\hline 2 & IPI00223367.5 & Uox & Uricase & \\
\hline 2 & IPI00125325.1 & Decr2 & Peroxisomal 2,4-dienoyl-CoA reductase & \\
\hline 2 & IPI00125813.1 & Dpp4 & Dipeptidyl peptidase (CD26) & {$[38,39]$} \\
\hline
\end{tabular}

${ }^{a}$ Columns left to right: Number of peptides identified for the protein by mass spectrometry; Protein ID; Gene name; Protein name; Reference (if any) reporting autoantibodies induced by the protein 
Table 2 Liver proteins with moderate DS-affinity

\begin{tabular}{|c|c|c|c|c|}
\hline \multicolumn{3}{|c|}{ a } & \multirow{2}{*}{$\begin{array}{l}\text { ANA (antinuclear autoantigens) } \\
\text { Histone H3.2 }\end{array}$} & \multirow{2}{*}{$\begin{array}{l}\text { Ref. } \\
{[41]}\end{array}$} \\
\hline 8 & IPI00230730.4 & Hist2h3b & & \\
\hline 4 & IPI00223713.5 & Hist1h1c & Histone H1.2 & [42] \\
\hline 2 & IPI00459318.1 & Hist1h2bp & Putative uncharacterized protein, histone & [9] \\
\hline 2 & IPI00136632.3 & H2afy3 & Histone $\mathrm{H} 2 \mathrm{~A}$ member $\mathrm{Y}_{3}$ & [43] \\
\hline 2 & IPI00320149.2 & H2afv & Histone H2A member $\mathrm{V}$ & [9] \\
\hline 6 & IPI00308706.4 & Rpl5 & $60 S$ ribosomal protein $L 5$ & \\
\hline 5 & IPI00127085.6 & Rpl10a & $60 S$ ribosomal protein L10a & \\
\hline 3 & IPI00555113.2 & Rpl18 & 605 ribosomal protein L18 & \\
\hline 3 & IPI00138892.2 & Uba52 & Ubiquitin-60S ribosomal protein $L 40$ & \\
\hline 2 & IPI00122598.3 & EG382723 & Similar to ribosomal protein L10 & \\
\hline 5 & IPI00339468.4 & Dhx9 & Isoform 2 of ATP-dependent RNA helicase, DNA helicase II & [44] \\
\hline 4 & IPI00121596.3 & Prpf8 & Pre-mRNA-processing-splicing factor 8 & \\
\hline 3 & IPI00109764.2 & Top1 & DNA topoisomerase 1 (Scl-70) & [45] \\
\hline 2 & IPI00322749.3 & Snrpd1 & Small nuclear ribonucleoprotein Sm D1 & [46] \\
\hline \multirow[t]{2}{*}{2} & IPI00120162.1 & Csnk2a1 & Casein kinase II subunit alpha & {$[17]$} \\
\hline & & & SMA (anti-smooth muscle autoantigens) / Cytoskeleton & \\
\hline 6 & IPI00400300.1 & Lmna & Isoform C of Lamin-A & {$[47]$} \\
\hline 4 & IPI00113886.1 & Lmnb2 & Isoform B3 of Lamin-B & [48] \\
\hline 2 & IPI00126191.5 & Lmnb2 & Isoform B2 of Lamin-B & [49] \\
\hline \multirow[t]{2}{*}{2} & IPI00113824.1 & Hspg2 & Basement membrane-specific heparan sulfate proteoglycan core protein & [50] \\
\hline & & & AMA (anti-mitochondrial autoantigens) & \\
\hline 5 & IPI00331555.2 & Bckdha & Branched chain keto acid dehydrogenase E1, alpha polypeptide (mitochondrion matrix) & [51] \\
\hline 5 & IPI00111877.1 & Ssbp1 & Single-stranded DNA-binding protein, mitochondria & \\
\hline 4 & IPI00153144.3 & Suox & Sulfite oxidase, mitochondria & [52] \\
\hline 3 & IPI00133208.3 & Hspa1l & Heat shock $70 \mathrm{kDa}$ protein $1 \mathrm{~L}$ & [53] \\
\hline 2 & IPI00323357.3 & Hspa8 & Heat shock cognate $71 \mathrm{kDa}$ protein & [54] \\
\hline 3 & IPI00420718.4 & Hmgcs2 & Hydroxymethylglutaryl-CoA synthase, mitochondria & [27] \\
\hline 3 & IPI00223092.5 & Hadha & Trifunctional enzyme subunit alpha, mitochondria & \\
\hline 3 & IPI00135651.1 & Slc25a13 & Calcium-binding mitochondrial carrier protein Aralar2 & \\
\hline 3 & IPI00111885.1 & Uqcrc1 & Cytochrome b-c1 complex subunit 1, mitochondria & [33] \\
\hline 3 & IPI00132799.4 & Clqbp & Complement component 1 q subcomponent binding protein & \\
\hline 2 & IPI00127841.3 & Slc25a5 & ADP/ATP translocase (mitochondrion inner membrane) & \\
\hline \multirow[t]{2}{*}{2} & IPI00387379.1 & Decr1 & 2,4-dienoyl-CoA reductase, mitochondria & \\
\hline & & & LKM (liver-kidney microsomal autoantigens) & \\
\hline 6 & IPI00117914.3 & Arg1 & Arginase-1 & {$[55]$} \\
\hline 6 & IPI00115679.1 & Ganab & Isoform 2 of Neutral alpha-glucosidase A & {$[56]$} \\
\hline 4 & IPI00621548.2 & Por & NADPH-cytochrome $\mathrm{P} 450$ reductase & {$[57]$} \\
\hline 4 & IPI00134691.3 & Ugt1a1 & UDP-glucuronosyltransferase 1-1 & [58] \\
\hline 2 & IPI00110556.1 & Cyp2e1 & Cytochrome P450 2E1 & {$[59,60]$} \\
\hline \multirow[t]{2}{*}{2} & IPI00321644.3 & Cyp2d26 & Cytochrome P450 2D26 (mouse) (LKM1 human) & [31] \\
\hline & & & Peroxisomal proteins & \\
\hline 6 & IPI00127558.3 & Acox1 & Peroxisomal acyl-coenzyme A oxidase & \\
\hline 6 & IPI00127276.1 & Ehhadh & Enoyl-Coenzyme A hydratase/3-hydroxyacyl CoA dehydrogenase (peroxisomal bifunctional enzyme) & [16] \\
\hline 2 & IPI00331628.5 & Hsd17b4 & Peroxisomal multifunctional enzyme type (17 beta-hydroxysteroid dehydrogenase type 4) & [61] \\
\hline
\end{tabular}


Table 2 Liver proteins with moderate DS-affinity (Continued)

\begin{tabular}{llll}
\hline & & ANA (antinuclear autoantigens) \\
\hline 4 & IPI00115599.6 & Hsd11b1 & Corticosteroid 11-beta-dehydrogenase isozyme \\
3 & IPI00117705.1 & Ddost & Dolichyl-diphosphooligosaccharide-protein glycosyltransferase 48 kDa subunit \\
3 & IPI00313236.3 & Slc27a5 & Bile acyl-CoA synthetase \\
2 & IPI00309035.2 & Rpn1 & Dolichyl-diphosphooligosaccharide-protein glycosyltransferase subunit 1 (ribophorin 1) \\
2 & IPI00127016.1 & Hsd17b6 & Hydroxysteroid 17-beta dehydrogenase \\
2 & IPI00130985.1 & Rdh7 & Retinol dehydrogenase \\
\hline
\end{tabular}

${ }^{a}$ Columns left to right: Number of peptides identified for the protein by mass spectrometry; Protein ID; Gene name; Protein name; Reference (if any) reporting autoantibodies induced by the protein

identified here have not been reported. Anti-smooth muscle autoantigens identified in the $0.4 \mathrm{M} \mathrm{NaCl}$ elution included various forms of tropomyosin, actinin, fibronectin, actin, myosin, lamin, spectrin, and tubulin. Among the 15 identified here, 12 are bona fide autoantigens. Among the 35 proteins associated with mitochondria, 32 are enzymes, with $8 / 32$ being reported autoantigens. These enzymes are from diverse families, e.g., dehydrogenases, synthases, acyltransferases, or carboxylases.

Similar to those identified in the $1.0 \mathrm{M}$ and $0.6 \mathrm{M}$ factions, the LKM autoantigens included members of cytochrome and UDP-glucuronosyltransferase families. In addition, 3 unrelated proteins, Mttp, Aldh1l1, and Ces1 were identified. Ces1 is a verified autoantigen. Six enzymes associated with the peroxisome were identified. Thus far, only peroxisomal sarcosine oxidase has been described to be an autoantigen. In addition to the above autoantigen categories, additional proteins were found associated with apoptosis and the proteasome (Table 3). Annexin A6 and 14-3-3 proteins are reported autoantigens. Members of the proteasome have also been reported as autoantigens.

The remaining 34 proteins could not easily be classified into particular categories. The majority of them are not yet characterized as autoantigens. However, some are reported autoantigens, such as calreticulin, calnexin, catenin, protein disulfide-isomerase, peroxiredoxin 4, vitamin D-binding protein, and complement C3 (Table 3).

\section{Discussion}

Under normal physiologic conditions, the immune system is designed to protect from infection and disease through intricate mechanisms that distinguish self from non-self. It is a mystery why and how the immune system is mistakenly triggered to attack the body's self. Autoimmune responses are causally linked to autoantibodies, autoreactive cells, or both. Despite advances in our understanding of the many facets of autoimmunity, the underlying molecular and cellular mechanisms that trigger autoimmunity remain largely unknown.
We are intrigued by the question why and how a vast number of diverse, seemingly functionally disconnected proteins in different parts of the body and with diverse structures and biological functions can all induce a converging autoimmune response, i.e., the production of autoantibodies by autoreactive B cells. Based on our previous studies [1, 2], we concluded that autoantigens share a common biochemical property in their binding affinity to dermatan sulfate (DS), also called chondroitin sulfate B, a glycosaminoglycan-type mucopolysaccharide found mostly in skin but also in blood vessels, heart valves, tendons, lungs, and other tissues. DS can directly bind molecules released from dying cells or other sources and form macromolecular DS-autoantigen complexes, and such complexes, in turn, can stimulate autoreactive $B$ cells through simultaneous engagement of multiple signaling molecules on the B cell surface to induce an activated B cell response. To further characterize our proposed "unifying principle of autoantigenicity" based on DS-affinity as a shared physicochemical property of autoantigens, we tested whether we could identify autoantigens from a specific parenchymal organ, and whether autoantigens showed preferential intrinsic biochemical propensity for high DS-affinity.

Autoimmune liver diseases result from the immune system mistakenly attacking hepatocytes or cholangiocytes in the liver [3-5]. Patients with these chronic conditions are usually initially rather asymptomatic, and autoantibody serology tests are often necessary to clarify the diagnosis [6, 7]. For example, while routine blood tests for liver enzymes can reveal patterns of hepatitis, further autoantibody tests are needed to diagnose autoimmune hepatitis. Autoantibody tests also help distinguish autoimmune hepatitis from other liver diseases, such as viral hepatitis or metabolic diseases such as Wilson disease.

Common autoimmune liver diseases include autoimmune hepatitis (AIH) [3], primary biliary cirrhosis (PBC) [4], and primary sclerosing cholangitis (PSC) [5]. An autoimmune liver disease panel (a series of tests that detect autoantibodies to common autoantigens associated 
Table 3 Liver proteins with weak DS-affinity

\begin{tabular}{|c|c|c|c|c|}
\hline \multicolumn{3}{|l|}{ a } & \multirow{2}{*}{$\begin{array}{l}\text { ANA (antinuclear autoantigens) } \\
\text { Isoform } 1 \text { of Splicing factor 3B subunit }\end{array}$} & \multirow{2}{*}{$\frac{\text { Ref. }}{[63]}$} \\
\hline 19 & IPI00122011.2 & Sf3b3 & & \\
\hline 14 & IPI00420807.3 & Sfrs1 & Isoform 1 of Splicing factor, arginine/serine-rich & \\
\hline 2 & IPI00153743.1 & Sfrs7 & Isoform 2 of Splicing factor, arginine/serine-rich & \\
\hline 4 & IPI00123604.4 & Rpsa & $40 S$ ribosomal protein SA & \\
\hline 3 & IPI00469260.3 & Eftud2 & 116 kDa U5 small nuclear ribonucleoprotein component & [64] \\
\hline 2 & IPI00170008.1 & Snrpa1 & U2 small nuclear ribonucleoprotein $A$ & [65] \\
\hline 2 & IPI00114052.1 & Snrpb & Small nuclear ribonucleoprotein-associated protein & [13] \\
\hline 2 & IPI00119220.1 & Snrpd2 & Small nuclear ribonucleoprotein Sm D2 & {$[66]$} \\
\hline 2 & IPI00226073.2 & Hnrnpf & Isoform 1 of Heterogeneous nuclear ribonucleoprotein F & \\
\hline \multirow[t]{2}{*}{2} & IPI00109860.3 & Rbm8a & Isoform 2 of RNA-binding protein 8 & \\
\hline & & & SMA (anti-smooth muscle autoantigens)/Cytoskeleton & \\
\hline 19 & |P|00123316.1 & Tpm1 & Isoform 1 of Tropomyosin alpha-1 chain & [67] \\
\hline 13 & IPI00169707.2 & Tpm3 & Tropomyosin 3, gamm & [68] \\
\hline 9 & IPI00230044.5 & Tpm3 & Isoform 2 of Tropomyosin alpha-3 chain & \\
\hline 2 & IPI00421223.3 & Tpm4 & Tropomyosin alpha-4 chain & [69] \\
\hline 13 & IPI00118899.1 & Actn4 & Alpha-actinin & [70] \\
\hline 9 & IPI00113539.2 & Fn1 & Fibronectin & [71] \\
\hline 7 & IPI00110850.1 & Actb & Actin, cytoplasmic & [72] \\
\hline 6 & IPI00110827.1 & Acta1 & Actin, alpha skeletal muscle & [72] \\
\hline 7 & IPI00265380.4 & Myh8 & Myosin-8 & [73] \\
\hline 3 & IPI00129404.1 & Myh6 & Myosin-6 & \\
\hline 3 & IPI00114894.1 & Myh11 & Isoform 1 of Myosin-1 & \\
\hline 5 & IPI00230394.5 & Lmnb1 & Lamin-B & [74] \\
\hline 4 & IPI00121892.9 & Spnb2 & Isoform 2 of Spectrin beta chain & [75] \\
\hline 3 & IPI00227299.6 & Vim & Vimentin & [69] \\
\hline \multirow[t]{2}{*}{2} & IPI00109061.1 & Tubb2b & Tubulin beta-2B chain & [76] \\
\hline & & & AMA (anti-mitochondrial autoantigens) & \\
\hline 52 & IPI00129526.1 & Hsp90b1 & Endoplasmin & [26] \\
\hline 9 & IPI00229080.7 & Hsp90ab1 & MCG1823 & \\
\hline 4 & IPI00330804.4 & Hsp90aa1 & Heat shock protein HSP 90-alpha & \\
\hline 39 & |P|00136213.5 & Sardh & Sarcosine dehydrogenase, mitochondrial & \\
\hline 31 & IPI00468481.2 & Atp5b & ATP synthase subunit beta, mitochondrial & [77] \\
\hline 21 & IPI00130280.1 & Atp5a1 & ATP synthase subunit alpha, mitochondrial & \\
\hline 27 & IPI00471246.2 & Ivd & Isovaleryl-CoA dehydrogenase, mitochondrial & \\
\hline 17 & IPI00134809.2 & Dlst & $\begin{array}{l}\text { Isoform } 1 \text { of Dihydrolipoyllysine-residue succinyltransferase component of 2-oxoglutarate dehydrogenase complex, } \\
\text { mitochondrial }\end{array}$ & [78] \\
\hline 2 & IPI00756386.1 & Dhtkd1 & Probable 2-oxoglutarate dehydrogenase E1 component DHKTD1, mitochondrial & \\
\hline 13 & IPI00331564.2 & Dld & Dihydrolipoyl dehydrogenase & \\
\hline 7 & IPI00130535.1 & Dbt & Lipoamide acyltransferase component of branched-chain alpha-keto acid dehydrogenase complex, mitochondrial & [78] \\
\hline 3 & IPI00153660.4 & Dlat & Dihydrolipoyllysine-residue acetyltransferase component of pyruvate dehydrogenase complex, mitochondrial & \\
\hline 13 & IPI00387491.1 & Aass & Alpha-aminoadipic semialdehyde synthase, mitochondrial & \\
\hline 13 & IPI00468653.4 & Pccb & Propionyl-CoA carboxylase beta chain, mitochondrial & \\
\hline 12 & IPI00330523.1 & Pcca & Propionyl-CoA carboxylase alpha chain, mitochondrial & \\
\hline 11 & IPI00110843.3 & Agmat & Agmatinase, mitochondrial & \\
\hline 9 & IPI00114710.2 & PCX & Pyruvate carboxylase, mitochondrial isoform 2 & \\
\hline
\end{tabular}


Table 3 Liver proteins with weak DS-affinity (Continued)

\begin{tabular}{|c|c|c|c|c|}
\hline \multicolumn{3}{|l|}{$a$} & \multirow{2}{*}{$\begin{array}{l}\text { ANA (antinuclear autoantigens) } \\
\text { Aldehyde dehydrogenase, mitochondrial }\end{array}$} & \multirow{2}{*}{$\frac{\text { Ref. }}{[27]}$} \\
\hline 7 & IPI00111218.1 & Aldh2 & & \\
\hline 4 & IPI00226430.2 & Acaa2 & 3-Ketoacyl-CoA thiolase, mitochondrial & \\
\hline 3 & IPI00119766.1 & Rdh16 & Retinol dehydrogenase 1 & \\
\hline 3 & IPI00405699.2 & Aldh4a1 & Delta-1-pyrroline-5-carboxylate dehydrogenase, mitochondrial & \\
\hline 3 & IPI00121309.2 & Ndufs3 & NADH dehydrogenase [ubiquinone] iron-sulfur protein 3, mitochondrial & \\
\hline 3 & IPI00753303.2 & Npl22 & Dihydrodipicolinate synthase-like, mitochondrial & \\
\hline 3 & IPI00169862.1 & Coq9 & Ubiquinone biosynthesis protein $\mathrm{COQ9}$, mitochondrial & \\
\hline 2 & IPI00323592.2 & Mdh2 & Malate dehydrogenase, mitochondrial & \\
\hline 2 & IPI00121105.2 & Hadh & Hydroxyacyl-coenzyme A dehydrogenase, mitochondrial & \\
\hline 2 & IPI00459725.2 & Idh3a & Isoform 1 of Isocitrate dehydrogenase [NAD] subunit alpha, mitochondrial & [79] \\
\hline 2 & IPI00133553.1 & Mut & Methylmalonyl-CoA mutase, mitochondrial & \\
\hline 2 & IPI00115607.3 & Hadhb & Trifunctional enzyme subunit beta, mitochondrial & \\
\hline 2 & IPI00130804.1 & Ech1 & Delta(3,5)-Delta(2,4)-dienoyl-CoA isomerase, mitochondrial & {$[80]$} \\
\hline 2 & IPI00469195.2 & Echdc2 & Isoform 1 of Enoyl-CoA hydratase domain-containing protein 2, mitochondrial & \\
\hline 2 & IPI00314909.2 & Agxt & Alanine-glyoxylate aminotransferase & \\
\hline 2 & IPI00226140.5 & Maob & Amine oxidase [flavin-containing] & [81] \\
\hline 2 & IPI00121440.4 & Etfb & Electron transfer flavoprotein subunit beta & [82] \\
\hline \multirow[t]{2}{*}{2} & IPI00454008.1 & Shmt2 & Serine hydroxymethyltransferase & \\
\hline & & & LKM (liver-kidney microsomal autoantigens) & \\
\hline 54 & IPI00309073.2 & Mttp & Microsomal triglyceride transfer protein & \\
\hline 33 & IPI00153317.3 & Aldh111 & 10-formyltetrahydrofolate dehydrogenase & \\
\hline 10 & IPI00111936.1 & Ugt1a9 & UDP-glucuronosyltransferase 1-9 & [31] \\
\hline 8 & IPI00762897.2 & Ugcgl1 & UDP-glucose:glycoprotein glucosyltransferase & \\
\hline 3 & IPI00127223.3 & Ugt2b36 & UDP-glucuronosyltransferase & \\
\hline 3 & IPI00114778.1 & Cyp2c37 & Cytochrome P450 2C37 & [83] \\
\hline 3 & IPI00131176.1 & mt-Co2 & Cytochrome c oxidase subunit 2 & \\
\hline 2 & IPI00323908.1 & Cyp2d10 & Cytochrome P450 2D10 & [83] \\
\hline 3 & IPI00331322.3 & Mgst1 & Microsomal glutathione S-transferase & \\
\hline \multirow[t]{2}{*}{9} & IPI00115867.4 & Ces1 & Liver carboxylesterase & [35] \\
\hline & & & Peroxisomal proteins & \\
\hline 6 & IPI00331596.6 & Pecr & Peroxisomal trans-2-enoyl-CoA reductase & \\
\hline 3 & IPI00134870.3 & Acox 2 & Peroxisomal acyl-coenzyme A oxidase & \\
\hline 5 & IPI00110719.1 & Pipox & Peroxisomal sarcosine oxidase & [84] \\
\hline 2 & IPI00130924.1 & Slc27a2 & Very long-chain acyl-CoA synthetaselow-den & \\
\hline 2 & IPI00121833.3 & Acaa1a & Acaa1b 3-ketoacyl-CoA thiolase A, peroxisomal & \\
\hline \multirow[t]{2}{*}{2} & IPI00111235.2 & Aldh3a2 & Fatty aldehyde dehydrogenase variant & \\
\hline & & & Apoptosis & \\
\hline 9 & IPI00310240.4 & Anxa6 & Annexin A6 isoform & [85] \\
\hline 5 & IPI00116498.1 & Ywhaz & 14-3-3 protein zeta/delta & [86] \\
\hline 5 & IPI00118384.1 & Ywhae & 14-3-3 protein epsilon & [87] \\
\hline \multirow[t]{2}{*}{5} & IPI00230707.6 & Ywhag & 14-3-3 protein gamma & [87] \\
\hline & & & Proteasome & \\
\hline 8 & IPI00113845.1 & Psmb1 & Proteasome subunit beta type-1 & [88] \\
\hline 4 & IPI00119239.2 & Psmb6 & Proteasome subunit beta type- 6 & \\
\hline 3 & IPI00116712.1 & Psmb8 & Proteasome subunit beta type- 8 & \\
\hline
\end{tabular}


Table 3 Liver proteins with weak DS-affinity (Continued)

\begin{tabular}{|c|c|c|c|c|}
\hline \multicolumn{3}{|l|}{$\bar{a}$} & \multirow{2}{*}{$\begin{array}{l}\text { ANA (antinuclear autoantigens) } \\
\text { Proteasome subunit beta type- } 2\end{array}$} & \multirow[t]{2}{*}{ Ref } \\
\hline 2 & IPI00128945.1 & Psmb2 & & \\
\hline 2 & IPI00129512.3 & Psmb4 & Proteasome subunit beta type- 4 & \\
\hline 2 & IPI00136483.1 & Psmb7 & Proteasome subunit beta type- 7 & \\
\hline 5 & IPI00331644.5 & Psma3 & Proteasome subunit alpha type-3 & [88] \\
\hline 4 & IPI00109122.1 & Psma8 & Proteasome subunit alpha type-7-like & \\
\hline 4 & IPI00131845.1 & Psma6 & Proteasome subunit alpha type- 6 & \\
\hline 4 & IPI00420745.7 & Psma2 & Proteasome subunit alpha type-2 & \\
\hline \multirow[t]{2}{*}{4} & IPI00277001.4 & Psma4 & Proteasome subunit alpha type- 4 & [89] \\
\hline & & & Miscellaneous & \\
\hline 68 & IPI00123639.1 & Calr & Calreticulin & [77] \\
\hline 67 & IPI00271951.5 & Pdia4 & Protein disulfide isomerase $\mathrm{A}$ & \\
\hline 61 & IPI00122815.3 & P4hb & Protein disulfide-isomerase & [90] \\
\hline 17 & IPI00222496.3 & Pdia6 & Putative uncharacterized protein & \\
\hline 2 & IPI00163011.2 & Txndc5 & Thioredoxin domain-containing protein & \\
\hline 20 & IPI00119618.1 & Canx & Calnexin & [91] \\
\hline 18 & IPI00622235.5 & Vcp & Transitional endoplasmic reticulum ATPase & [92] \\
\hline 14 & IPI00125514.1 & Entpd5 & Ectonucleoside triphosphate diphosphohydrolase 5 & \\
\hline 11 & IPI00475154.1 & Rpn2 & Dolichyl-diphosphooligosaccharide-protein glycosyltransferase subunit & \\
\hline 2 & IPI00309035.2 & Rpn1 & Dolichyl-diphosphooligosaccharide--protein glycosyltransferase subunit & \\
\hline 11 & IPI00112719.1 & Alad & Delta-aminolevulinic acid dehydratase & \\
\hline 10 & IPI00115680.1 & Prkcsh & Isoform 1 of Glucosidase 2 subunit beta & \\
\hline 7 & IPI00119063.2 & Lrp1 & Pro-low-density lipoprotein receptor-related protein (alpha-2-macroglobulin receptor, apolipoprotein E receptor) & \\
\hline 2 & IPI00624663.3 & Pzp & Alpha-2-macroglobulin & \\
\hline 7 & IPI00135512.1 & Cnpy2 & Protein canopy homolog 2 & \\
\hline 6 & IPI00316314.1 & Hacl1 & 2-hydroxyacyl-CoA lyase & \\
\hline 6 & IPI00116254.1 & $\operatorname{Prd} \times 4$ & Peroxiredoxin-4 & [93] \\
\hline 6 & IPI00125899.1 & Ctnnb1 & Catenin beta-1 & \\
\hline 4 & IPI00112963.1 & Ctnna1 & Catenin alpha-1 & [94] \\
\hline 5 & IPI00113869.1 & Bsg & Isoform 2 of Basigin (M6, EMMPRIN, TCSF, CD147) & \\
\hline 4 & IPI00126184.7 & Gc & Vitamin D-binding protein & [95] \\
\hline 4 & IPI00123342.4 & Hyou1 & Hypoxia up-regulated protein & \\
\hline 3 & IPI00130950.1 & Bhmt & Betaine--homocysteine S-methyltransferase & [96] \\
\hline 3 & IPI00134058.3 & Erp44 & Endoplasmic reticulum resident protein ERp44 & \\
\hline 3 & IPI00387282.4 & Aadac & Arylacetamide deacetylase & \\
\hline 3 & IPI00122346.2 & Ssr4 & Signal sequence receptor, delta & \\
\hline 3 & IPI00317740.5 & Gnb2l1 & Guanine nucleotide-binding protein subunit beta-2-like & \\
\hline 3 & IPI00319973.3 & Pgrmc1 & Membrane-associated progesterone receptor component & \\
\hline 2 & IPI00279218.1 & Apeh & Isoform 2 of Acylamino-acid-releasing enzyme & \\
\hline 2 & IPI00323624.3 & C3 & Isoform Long of Complement C3 & [97] \\
\hline 2 & IPI00116432.1 & Fmol & Dimethylaniline monooxygenase [N-oxide-forming] & \\
\hline 2 & IPI00114044.1 & Man2a1 & Alpha-mannosidase & \\
\hline 2 & IPI00312018.6 & Mlec & Malectin & \\
\hline 2 & IPI00115241.1 & Mup4 & Major urinary protein 4 & \\
\hline
\end{tabular}

${ }^{a}$ Columns left to right: Number of peptides identified for the protein by mass spectrometry; Protein ID; Gene name; Protein name; Reference (if any) reporting autoantibodies induced by the protein 
with these diseases) include anti-liver-kidney microsomal antibodies (LKM), anti-mitochondrial antibodies (AMA), anti-nuclear antibodies (ANA), and anti-smooth muscle antibodies (SMA). AIH is further classified to two types, type I is defined by positive ANA and SMA, whereas type 2 is associated with anti-KLM autoantibodies. ANA occur in a wide variety of systemic autoimmune diseases, such as systemic lupus erythematosus, rheumatoid arthritis, Sjögren syndrome, and systemic sclerosis. Lupus hepatitis is regarded as a distinct manifestation of SLE [98]. The identification of 41 confirmed or putative ANA autoantigens from liver tissue uncovered by our study may perhaps explain the overlap autoantibody profile and clinical manifestations between lupus and AIH. AMA are hallmark diagnostic markers for PBC. In PBC, the targets are small bile ducts, but the prototypic serologic response is the production of a multilineage immune response to mitochondrial autoantigens. AMA are detected in 90$95 \%$ of $\mathrm{PBC}$ patients, although their presence is extremely low in the general population (varying between 0.16 and 1\%) [99]. More than 60 autoantibodies have been detected in patients with PBC [99]. In our current study, we identified 54 verified and putative autoantigens associated with mitochondria.

Based on all of our observation so far, we find that autoantigens with the strongest DS affinity are typically DNA- and RNA-binding proteins. Other autoantigens largely display moderate to weak DS affinity. However, it should be noted that our definition of DS binding strength is arbitrary, with DS-autoAg complexes dissociable at 1.0, 0.6, and $0.4 \mathrm{M}$ ionic strength defined as strongly, moderately, and weakly binding, respectively. All of these DS-binding proteins would be expected to remain in complexed forms with DS under physiologic conditions. For example, cytochrome P450 2D6 (CYP2D6) is the major autoantigen of LKM1 autoantibodies [100], but its mouse homologues (Cyp2d26 and Cyp2d10) were found to possess only moderate to weak DS affinity (Tables 2 and 3). As another example, PDC-E2 is a major autoantigen in PBC patients, but several components of the PDC (pyruvate dehydrogenase complex) were only identified in the weak but not the strong DS affinity fraction of this study (Table 3). Hence, these results suggest that proteins only need to exhibit some (sufficient) DS affinity to become potentially autoantigenic. It is also possible that in toto weakly DS-binding proteins may contain fragment epitopes with strong DS affinity, and such epitopes could determine the autoantigenicity of the protein.

The liver is the largest internal organ, the largest gland of the human body, and also the largest reservoir of human proteins. The liver serves hundreds of physiological functions, including removal of toxic substance, storage of glycogen, decomposition of red blood cells, production of bile and hormones, and synthesis of plasma proteins. Transcriptome analysis shows that 59\% $(n=11$, 553) of all human proteins $(n=19,613)$ are expressed in the liver (The Human Protein Atlas). It should be noted that our DS-affinity approach provided a significant enrichment of liver protein autoantigens, yielding only a little over 200 proteins (i.e., around 1\% of the total human proteome) as bona fide verified or potential autoantigens.

\section{Conclusions}

Our study of DS-affinity enrichment of the liver proteome produced a comprehensive autoantigen-ome that includes 104 bona fide autoantigens and 108 potential autoantigens for autoimmune liver diseases. These autoantigens fell into the classical categories of autoantibodies for autoimmune liver diseases. Our study provides further support to a model in which DS-affinity is a distinct

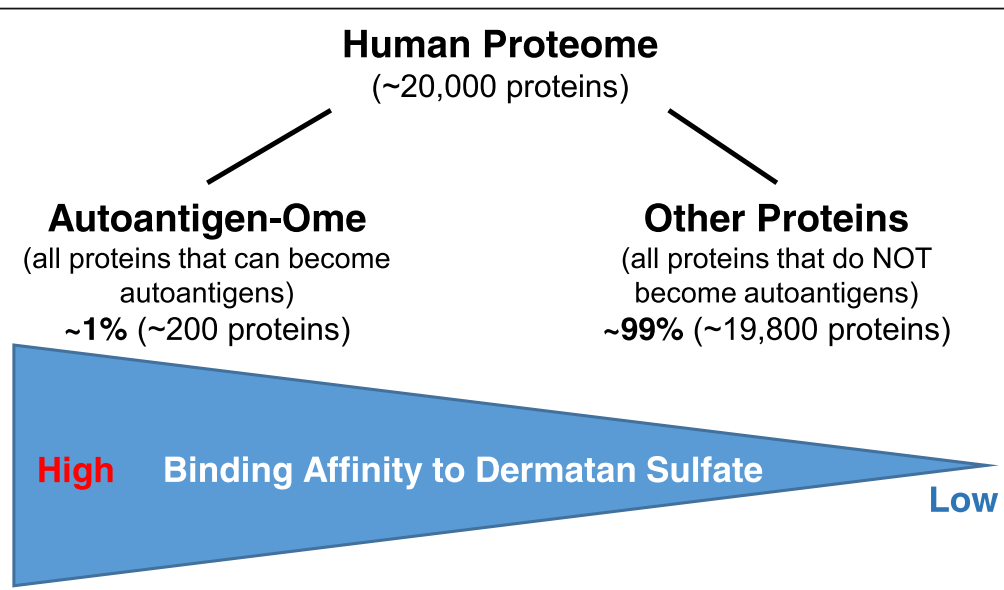

Fig. 1 Model illustrating our hypothesis that binding affinity to dermatan sulfate is a distinct biochemical property characterizing (a small subset of) human proteins (estimated at 1\%) that can become human autoantigens, whereas the majority of proteins (estimated at $\sim 99 \%)$ that lack binding affinity have a much lower propensity to become targets of autoimmunity 
biochemical property of proteins that can become autoantigens, whereas proteins that lack DS-affinity have a much lower propensity to be targets of autoimmunity (Fig. 1). These results may help in the further characterization of autoantigenic molecules and thus point to new innovative directions in autoimmunity research.

\section{Abbreviations}

AlH: Autoimmune hepatitis; AMA: Anti-mitochondrial autoantibodies; DS: Dermatan sulfate; LKM: Liver-kidney microsomal autoantigens; PBC: Primary biliary cirrhosis; PSC: Primary sclerosing cholangitis; SMA: Smooth muscle autoantibodies

\section{Acknowledgements}

We thank the Taplin Biological Mass Spectrometry facility at Harvard Medical School for expert help with protein sequencing. We thank Michael W. Roehrl for editing the manuscript.

\section{Authors' contributions}

WZ carried out the experiments, analyzed the data, and reviewed the manuscript. JHR assisted in experiments and reviewed the manuscript. MHR consulted on the study, evaluated data, and edited the manuscript. JYW directed the study, analyzed data, conducted literature searches, and wrote the manuscript. All authors have read and approved the final manuscript.

\section{Funding}

This study was partially funded by the NIH (R01 Al068826 to JYW) and Curandis. The funding bodies were not involved in the design of the study and the collection, analysis, and interpretation of data and in writing the manuscript.

\section{Availability of data and materials}

All data generated or analyzed during this study are included in this published article.

\section{Ethics approval and consent to participate}

The mouse tissue use was approved by the Institutional Animal Care and Use Committee (IACUC) of Brigham and Women's Hospital (Boston, MA). All animal care was provided according to institutional, local, state, and federal regulations at the Brigham and Women's Hospital research animal facility.

\section{Consent for publication}

Not applicable.

\section{Competing interests}

WZ and JHR were supported by the $\mathrm{NIH}$ during the course of this study and declare no competing interests. MP Biomedicals is the current employer of JHR and has neither relation to nor made contribution to the study and has not had any role in this research. MHR declares no competing interests. JYW is a cofounder and shareholder of Curandis and declares no other competing interests.

\section{Author details}

'Department of Gastroenterology, Affiliated Hospital of Guizhou Medical University, Guiyang, Guizhou, China. ${ }^{2}$ MP Biochemicals, Auckland, New Zealand. ${ }^{3}$ Department of Pathology, Memorial Sloan Kettering Cancer Center, New York, USA. ${ }^{4}$ Curandis, New York, USA.

Received: 6 December 2018 Accepted: 19 June 2019

Published online: 26 June 2019

References

1. Wang JY, Lee J, Yan M, Rho JH, Roehrl MH. Dermatan sulfate interacts with dead cells and regulates CD5(+) B-cell fate: implications for a key role in autoimmunity. Am J Pathol. 2011;178(5):2168-76.

2. Rho JH, Zhang W, Murali M, Roehrl MH, Wang JY. Human proteins with affinity for dermatan sulfate have the propensity to become autoantigens. Am J Pathol. 2011:178(5):2177-90.

3. Terziroli Beretta-Piccoli B, Mieli-Vergani G, Vergani D. Autoimmune hepatitis: standard treatment and systematic review of alternative treatments. World Gastroenterol. 2017;23(33):6030-48.
4. Trivedi HD, Lizaola B, Tapper EB, Bonder A. Primary biliary cholangitis: new treatments for an old disease. Frontline Gastroenterol. 2017;8(1):29-36.

5. Arndtz K, Hirschfield GM. Primary sclerosing cholangitis and the management of uncertainty and complexity. Frontline Gastroenterol. 2017; 8(4):260-6.

6. Sebode M, Weiler-Normann C, Liwinski T, Schramm C. Autoantibodies in autoimmune liver disease-clinical and diagnostic relevance. Front Immunol. 2018;9:609.

7. Toh BH. Diagnostic autoantibodies for autoimmune liver diseases. Clin Transl Immunology. 2017;6(5):e139.

8. Dieker J, Berden JH, Bakker M, Briand JP, Muller S, Voll R, Sjowall C, Herrmann M, Hilbrands LB, van der Vlag J. Autoantibodies against modified histone peptides in SLE patients are associated with disease activity and lupus nephritis. PLoS One. 2016;11(10):e0165373.

9. Burlingame RW, Rubin RL. Autoantibody to the nucleosome subunit ( $\mathrm{H} 2 \mathrm{~A}-$ $\mathrm{H} 2 \mathrm{~B})$-DNA is an early and ubiquitous feature of lupus-like conditions. Mol Biol Rep. 1996:23(3-4):159-66.

10. Kwon YS, Chung J, Shin GT, Lee SY, Jang YJ. Variable region genes of human monoclonal autoantibodies to histones $\mathrm{H} 2 \mathrm{~A}$ and $\mathrm{H} 2 \mathrm{~B}$ from a systemic lupus erythematosus patient. Mol Immunol. 2005;42(3):311-7.

11. Wesierska-Gadek J, Penner E, Lindner H, Hitchman E, Sauermann G. Autoantibodies against different histone $\mathrm{H} 1$ subtypes in systemic lupus erythematosus sera. Arthritis Rheum. 1990;33(8):1273-8.

12. McClain MT, Ramsland PA, Kaufman KM, James JA. Anti-sm autoantibodies in systemic lupus target highly basic surface structures of complexed spliceosomal autoantigens. J Immunol. 2002;168(4):2054-62.

13. Wang H, Demirkan G, Bian X, Wallstrom G, Barker K, Karthikeyan K, Tang Y, Pasha SF, Leighton JA, Qiu J, et al. Identification of antibody against SNRPB, small nuclear Ribonucleoprotein-associated proteins B and B', as an autoantibody marker in Crohn's disease using an Immunoproteomics approach. J Crohns Colitis. 2017;11(7):848-56.

14. Mesa A, Somarelli JA, Wu W, Martinez L, Blom MB, Greidinger EL, Herrera RJ Differential immunoglobulin class-mediated responses to components of the U1 small nuclear ribonucleoprotein particle in systemic lupus erythematosus and mixed connective tissue disease. Lupus. 2013;22(13): 1371-81.

15. Reuter R, Rothe S, Habets W, Van Venrooij WJ, Luhrmann R. Autoantibody production against the $U$ small nuclear ribonucleoprotein particle proteins E, F and $G$ in patients with connective tissue diseases. Eur J Immunol. 1990; 20(2):437-40.

16. Absi M, La Vergne JP, Marzouki A, Giraud F, Rigal D, Reboud AM, Reboud JP, Monier JC. Heterogeneity of ribosomal autoantibodies from human, murine and canine connective tissue diseases. Immunol Lett. 1989;23(1):35-41.

17. Neu E, von Mikecz AH, Hemmerich $\mathrm{PH}$, Peter $\mathrm{HH}$, Fricke $M$, Deicher $\mathrm{H}$ Genth E, Krawinkel U. Autoantibodies against eukaryotic protein L7 in patients suffering from systemic lupus erythematosus and progressive systemic sclerosis: frequency and correlation with clinical, serological and genetic parameters. The SLE study group. Clin Exp Immunol. 1995;100(2): 198-204.

18. Perone D, Santos MA, Peixoto MS, Cicarelli RM. Trypanosoma cruzi: identification and characterization of a novel ribosomal protein L27 (TcrL27) that cross-reacts with an affinity-purified anti-Sm antibody. Parasitology. 2003;126(Pt 6):577-83.

19. Becker A, Ludwig N, Keller A, Tackenberg B, Eienbroker C, Oertel WH, Fassbender K, Meese E, Ruprecht K. Myasthenia gravis: analysis of serum autoantibody reactivities to 1827 potential human autoantigens by protein macroarrays. PLoS One. 2013;8(3):e58095.

20. Forne I, Carrascal M, Martinez-Lostao L, Abian J, Rodriguez-Sanchez JL, Juarez C. Identification of the autoantigen HB as the barrier-toautointegration factor. J Biol Chem. 2003;278(50):50641-4.

21. Azizah MR, Azila MN, Zulkifli MN, Norita TY. The prevalence of antinuclear, anti-dsDNA, anti-Sm and anti-RNP antibodies in a group of healthy blood donors. Asian Pac J Allergy Immunol. 1996;14(2):125-8.

22. Migliorini $P$, Baldini $C$, Rocchi V, Bombardieri S. Anti-Sm and anti-RNP antibodies. Autoimmunity. 2005;38(1):47-54

23. Bledzhyants DA, Muratov RM, Movsesyan RR, Podlubnaya ZA Autoantibodies to myosin light chains in the blood as early marker of myocardial injury after aortocoronary bypass surgery. Bull Exp Biol Med. 2007; 144(2):241-5

24. Latif N, Baker CS, Dunn MJ, Rose ML, Brady P, Yacoub MH. Frequency and specificity of antiheart antibodies in patients with dilated cardiomyopathy 
detected using SDS-PAGE and western blotting. J Am Coll Cardiol. 1993; 22(5):1378-84.

25. Malka D, Pham BN, Courvalin JC, Corbic M, Pessayre D, Erlinger S. Acute hepatitis caused by alverine associated with anti-Lamin a and $\mathrm{C}$ autoantibodies. J Hepatol. 1997;27(2):399-403.

26. Kadam KM, Mande PV, Gawas N, Ahire S, Khole LV. Autoantibodies to heatshock protein, HSPA5, and epitope spreading: high-dose dexamethasone therapy rescues ovarian function in experimental autoimmune ovarian insufficiency mouse model. Am J Reprod Immunol. 2016;75(5):580-93.

27. Toivola DM, Habtezion A, Misiorek JO, Zhang L, Nystrom JH, Sharpe O, Robinson WH, Kwan R, Omary MB. Absence of keratin 8 or 18 promotes antimitochondrial autoantibody formation in aging male mice. FASEB J. 2015;29(12):5081-9.

28. Mayasari N, Van Knegsel AT, de Vries RG, Kemp B, Parmentier HK. Natural autoantibodies in Bos taurus calves during the first twelve weeks of life. Vet Immunol Immunopathol. 2016;178:70-8.

29. Okubo M, Yamamoto K, Kato T, Matsuura N, Nishimaki T, Kasukawa R, Ito K, Mizushima Y, Nishioka K. Detection and epitope analysis of autoantigenreactive $\mathrm{T}$ cells to the U1-small nuclear ribonucleoprotein a protein in autoimmune disease patients. J Immunol. 1993;151(2):1108-15.

30. Li L, Chen $\mathrm{SH}, \mathrm{Yu} \mathrm{CH}$, Li YM, Wang SQ. Identification of hepatocellularcarcinoma-associated antigens and autoantibodies by serological proteome analysis combined with protein microarray. J Proteome Res. 2008;7(2):611-20.

31. Manns MP, Obermayer-Straub P. Cytochromes P450 and uridine triphosphate-glucuronosyltransferases: model autoantigens to study druginduced, virus-induced, and autoimmune liver disease. Hepatology. 1997; 26(4):1054-66.

32. Obermayer-Straub P, Manns MP. Cytochromes P450 and UDP-glucuronosyltransferases as hepatocellular autoantigens. Baillieres Clin Gastroenterol. 1996;10(3):501-32.

33. Hao S, Fu R, Wang H, Shao Z. Screening novel autoantigens targeted by serum IgG autoantibodies in immunorelated pancytopenia by SEREX. Int J Hematol. 2017;106(5):622-30.

34. Edassery SL, Shatavi SV, Kunkel JP, Hauer C, Brucker C, Penumatsa K, Yu Y, Dias JA, Luborsky JL. Autoantigens in ovarian autoimmunity associated with unexplained infertility and premature ovarian failure. Fertil Steril. 2010;94(7): 2636-41.

35. Smith GC, Kenna JG, Harrison DJ, Tew D, Wolf CR. Autoantibodies to hepatic microsomal carboxylesterase in halothane hepatitis. Lancet. 1993;342(8877): 963-4.

36. Miura $H$, Tobe T, Nakano Y. Analysis of epitope regions for autoantibodies in catalase. Immunol Investig. 2010;39(8):796-806.

37. D'Souza A, Kurien BT, Rodgers R, Shenoi J, Kurono S, Matsumoto H, Hensley K, Nath SK, Scofield RH. Detection of catalase as a major protein target of the lipid peroxidation product 4-HNE and the lack of its genetic association as a risk factor in SLE. BMC Med Genet. 2008:9:62.

38. Kubota T, lizuka H, Bachovchin WW, Stollar BD. Dipeptidyl peptidase IV (DP IV) activity in serum and on lymphocytes of MRL/Mp-lpr/lpr mice correlates with disease onset. Clin Exp Immunol. 1994;96(2):292-6.

39. Vojdani A, Bazargan M, Vojdani E, Samadi J, Nourian AA, Eghbalieh N, Cooper EL. Heat shock protein and gliadin peptide promote development of peptidase antibodies in children with autism and patients with autoimmune disease. Clin Diagn Lab Immunol. 2004;11(3):515-24.

40. Shi L, Gehin T, Chevolot Y, Souteyrand E, Mange A, Solassol J, Laurenceau E. Anti-heat shock protein autoantibody profiling in breast cancer using customized protein microarray. Anal Bioanal Chem. 2016;408(5):1497-506.

41. Chen M, Shirai M, Czaja AJ, Kurokohchi K, Arichi T, Arima K, Kodama T, Nishioka M. Characterization of anti-histone antibodies in patients with type 1 autoimmune hepatitis. J Gastroenterol Hepatol. 1998;13(5):483-9.

42. Konikoff F, Swissa M, Shoenfeld Y. Autoantibodies to histones and their subfractions in chronic liver diseases. Clin Immunol Immunopathol. 1989; 51(1):77-82

43. Khan MA, Dixit K, Uddin M, Malik A, Alam K. Role of peroxynitrite-modified $\mathrm{H} 2 \mathrm{~A}$ histone in the induction and progression of rheumatoid arthritis. Scand J Rheumatol. 2012;41(6):426-33.

44. Xu Y, Liu AJ, Gao YX, Hu MG, Zhao GD, Zhao ZM, Liu R. Expression of Ku86 and presence of Ku86 antibody as biomarkers of hepatitis B virus related hepatocellular carcinoma. Dig Dis Sci. 2014;59(3):614-22.

45. Mahler M, Silverman ED, Schulte-Pelkum J, Fritzler MJ. Anti-Scl-70 (topo-1) antibodies in SLE: myth or reality? Autoimmun Rev. 2010;9(11):756-60.
46. Brahms H, Raymackers J, Union A, de Keyser F, Meheus L, Luhrmann R. The C-terminal RG dipeptide repeats of the spliceosomal Sm proteins D1 and D3 contain symmetrical dimethylarginines, which form a major B-cell epitope for anti-Sm autoantibodies. J Biol Chem. 2000;275(22):17122-9.

47. Lussiez V, Combe B, Graafland H, Rucheton M, Sany J. Anti-Sm and anti-RNP antibodies detected by immunoblotting in disseminated lupus erythematosus. Rev Rhum Mal Osteoartic. 1989;56(1):35-8.

48. Mjelle JE, Rekvig OP, Fenton KA. Nucleosomes possess a high affinity for glomerular laminin and collagen IV and bind nephritogenic antibodies in murine lupus-like nephritis. Ann Rheum Dis. 2007:66(12):1661-8.

49. Meyer O, Kuntz D, Kahn MF, Bourgeois R, Haim T. Characterization by immunoblotting (western blot) of anti-RNP antibodies in 36 connective tissue disease patients of whom 26 had mixed connective tissue disease. Comparison with 28 lupus patients with anti-Sm antibodies. Rev Rhum Mal Osteoartic. 1989;56(1):39-44.

50. Fillit H, Shibata S, Sasaki T, Spiera H, Kerr LD, Blake M. Autoantibodies to the protein core of vascular basement membrane heparan sulfate proteoglycan in systemic lupus erythematosus. Autoimmunity. 1993;14(3):243-9.

51. Kaburaki J, Stollar BD. Identification of human anti-DNA, anti-RNP, anti-SM, and anti-SS-A serum antibodies bearing the cross-reactive 16/6 idiotype. J Immunol. 1987;139(2):385-92.

52. Preuss B, Berg C, Altenberend F, Gregor M, Stevanovic S, Klein R. Demonstration of autoantibodies to recombinant human sulphite oxidase in patients with chronic liver disorders and analysis of their clinical relevance. Clin Exp Immunol. 2007;150(2):312-21.

53. Zieve GW, Khusial PR. The anti-Sm immune response in autoimmunity and cell biology. Autoimmun Rev. 2003;2(5):235-40.

54. Jaekel HP, Klopsch T, Benkenstein B, Grobe N, Baldauf A, Schoessler W, Werle E. Reactivities to the Sm autoantigenic complex and the synthetic SmD1-aa83-119 peptide in systemic lupus erythematosus and other autoimmune diseases. J Autoimmun. 2001;17(4):347-54.

55. Kimura M, Tatsumi KI, Tada H, Ikemoto M, Fukuda Y, Kaneko A, Kato M, Hidaka Y, Amino N. Enzyme immunoassay for autoantibodies to human liver-type arginase and its clinical application. Clin Chem. 2000:46(1):112-7.

56. Kit Y, Starykovych M, Vajrychova M, Lenco J, Zastavna D, Stoika R. Detection of novel auto-antigens in patients with recurrent miscarriage: description of an approach and preliminary findings. Croat Med J. 2014;55(3):259-64.

57. Reuter R, Luhrmann R. Immunization of mice with purified U1 small nuclear ribonucleoprotein (RNP) induces a pattern of antibody specificities characteristic of the anti-Sm and anti-RNP autoimmune response of patients with lupus erythematosus, as measured by monoclonal antibodies. Proc Natl Acad Sci U S A. 1986;83(22):8689-93.

58. Habets WJ, de Rooij DJ, Hoet MH, van de Putte LB, van Venrooij WJ. Quantitation of anti-RNP and anti-Sm antibodies in MCTD and SLE patients by immunoblotting. Clin Exp Immunol. 1985;59(2):457-66.

59. Reuter R, Appel B, Bringmann P, Rinke J, Luhrmann R. 5'-terminal caps of snRNAs are reactive with antibodies specific for 2,2,7-trimethylguanosine in whole cells and nuclear matrices. Double-label immunofluorescent studies with anti-m3G antibodies and with anti-RNP and anti-Sm autoantibodies. Exp Cell Res. 1984;154(2):548-60.

60. Marti A, Matsuda M, Sihag RK, Eliceiri GL. The small nuclear ribonucleoproteins that react with anti-Sm and anti-RNP antibodies. Biochem Biophys Res Commun. 1984:123(1):345-51.

61. Dinkel K, Rickert M, Moller G, Adamski J, Meinck HM, Richter W. Stiff-man syndrome: identification of 17 beta-hydroxysteroid dehydrogenase type 4 as a novel 80-kDa antineuronal antigen. J Neuroimmunol. 2002;130(1-2): 184-93.

62. Kumagai T, Uchida M, Okumura N, Kameko M, Katsuyama T. Kanai M: [enzyme-linked immunosorbent assay for the detection of immunoglobulin class-specific anti-RNP and anti-Sm antibodies]. Rinsho Byori. 1988;36(6):699-704

63. Hwang HM, Heo CK, Lee HJ, Kwak SS, Lim WH, Yoo JS, Yu DY, Lim KJ, Kim JY, Cho EW. Identification of anti-SF3B1 autoantibody as a diagnostic marker in patients with hepatocellular carcinoma. J Transl Med. 2018;16(1):177.

64. Okano Y, Targoff IN, Oddis CV, Fujii T, Kuwana M, Tsuzaka K, Hirakata M, Mimori T, Craft J, Medsger TA Jr. Anti-U5 small nuclear ribonucleoprotein (snRNP) antibodies: a rare anti-U snRNP specificity. Clin Immunol Immunopathol. 1996;81(1):41-7.

65. Mimori T, Hinterberger M, Pettersson I, Steitz JA. Autoantibodies to the U2 small nuclear ribonucleoprotein in a patient with scleroderma-polymyositis overlap syndrome. J Biol Chem. 1984;259(1):560-5. 
66. Lehmeier T, Foulaki K, Luhrmann R. Evidence for three distinct D proteins, which react differentially with anti-Sm autoantibodies, in the cores of the major snRNPs U1, U2, U4/U6 and U5. Nucleic Acids Res. 1990;18(22):6475-84.

67. Mahesh SP, Li Z, Buggage R, Mor F, Cohen IR, Chew EY, Nussenblatt RB. Alpha tropomyosin as a self-antigen in patients with Behcet's disease. Clin Exp Immunol. 2005;140(2):368-75.

68. Gajbhiye R, Sonawani A, Khan S, Suryawanshi A, Kadam S, Warty N, Raut V, Khole $\mathrm{V}$. Identification and validation of novel serum markers for early diagnosis of endometriosis. Hum Reprod. 2012;27(2):408-17.

69. Kimura A, Sakurai T, Yamada M, Koumura A, Hayashi Y, Tanaka Y, Hozumi I, Ohtaki H, Chousa M, Takemura M, et al. Anti-endothelial cell antibodies in patients with cerebral small vessel disease. Curr Neurovasc Res. 2012;9(4): 296-301.

70. Renaudineau Y, Dalekos GN, Guequen P, Zachou K, Youinou P. Anti-alphaactinin antibodies cross-react with anti-ssDNA antibodies in active autoimmune hepatitis. Clin Rev Allergy Immunol. 2008;34(3):321-5.

71. van Beers JJ, Willemze A, Stammen-Vogelzangs J, Drijfhout JW, Toes RE, Pruijn GJ. Anti-citrullinated fibronectin antibodies in rheumatoid arthritis are associated with human leukocyte antigen-DRB1 shared epitope alleles. Arthritis Res Ther. 2012;14(1):R35.

72. Orth T, Gerken G, Kellner R, Meyer zum Buschenfelde KH, Mayet WJ. Actin is a target antigen of anti-neutrophil cytoplasmic antibodies (ANCA) in autoimmune hepatitis type-1. J Hepatol. 1997;26(1):37-47.

73. Caforio AL, Grazzini M, Mann JM, Keeling PJ, Bottazzo GF, McKenna WJ, Schiaffino S. Identification of alpha- and beta-cardiac myosin heavy chain isoforms as major autoantigens in dilated cardiomyopathy. Circulation. 1992; 85(5):1734-42.

74. Senecal JL, Rauch J, Grodzicky T, Raynauld JP, Uthman I, Nava A, Guimond $M$, Raymond Y. Strong association of autoantibodies to human nuclear Lamin B1 with lupus anticoagulant antibodies in systemic lupus erythematosus. Arthritis Rheum. 1999:42(7):1347-53.

75. Garbarz M, Dhermy D, Bournier O, Bezeaud A, Boivin P. Anti-spectrin in sera containing smooth muscle autoantibodies from patients with chronic active hepatitis. Clin Exp Immunol. 1981;43(1):87-93.

76. Bansal D, Herbert F, Lim P, Deshpande P, Becavin C, Guiyedi V, de Maria I, Rousselle JC, Namane A, Jain R, et al. IgG autoantibody to brain beta tubulin III associated with cytokine cluster-II discriminate cerebral malaria in Central India. PLoS One. 2009:4(12):e8245

77. Le Naour F, Brichory F, Misek DE, Brechot C, Hanash SM, Beretta L. A distinct repertoire of autoantibodies in hepatocellular carcinoma identified by proteomic analysis. Mol Cell Proteomics. 2002;1(3):197-203.

78. Fregeau DR, Prindiville T, Coppel RL, Kaplan M, Dickson ER, Gershwin ME. Inhibition of alpha-ketoglutarate dehydrogenase activity by a distinct population of autoantibodies recognizing dihydrolipoamide succinyltransferase in primary biliary cirrhosis. Hepatology. 1990;11(6):975-81.

79. Carlsson L, Ronquist G, Nilsson BO, Larsson A. Dominant prostasome immunogens for sperm-agglutinating autoantibodies of infertile men J Androl. 2004:25(5):699-705.

80. Dai L, Li J, Tsay JJ, Yie TA, Munger JS, Pass H, Rom WN, Tan EM, Zhang JY. Identification of autoantibodies to ECH1 and HNRNPA2B1 as potential biomarkers in the early detection of lung cancer. Oncoimmunology. 2017; 6(5):e1310359.

81. Pons C, Dansette PM, Gregeois J, Homberg JC, Billett EE, Mansuy D. Human anti-mitochondria autoantibodies appearing in iproniazid-induced immunoallergic hepatitis recognize human liver monoamine oxidase B. Biochem Biophys Res Commun. 1996;218(1):118-24.

82. Kemp EH, Ridgway JN, Smith KA, Watson PF, Weetman AP. Autoantibodies to the flavoprotein subunit of succinate dehydrogenase: analysis of specificity in autoimmune thyroid disease. Clin Endocrinol. 2000;53(3):291-9.

83. Loeper J, Descatoire V, Maurice M, Beaune P, Belghiti J, Houssin D, Ballet F Feldmann G, Guengerich FP, Pessayre D. Cytochromes P-450 in human hepatocyte plasma membrane: recognition by several autoantibodies. Gastroenterology. 1993;104(1):203-16.

84. Cicek G, Vuorinen T, Stahle I, Stepanek P, Freudenberg N, Brandsch R. Coxsackievirus B3 infection induces anti-flavoprotein antibodies in mice. Clin Exp Immunol. 2000;122(3):404-9.

85. Seko Y, Matsumoto A, Fukuda T, Imai Y, Fujimura T, Taka H, Mineki R, Murayama K, Hirata Y, Nagai R. A case of neonatal lupus erythematosus presenting delayed dilated cardiomyopathy with circulating autoantibody to annexin A6. Int Heart J. 2007;48(3):407-15.
86. Chakravarti R, Gupta K, Swain M, Willard B, Scholtz J, Svensson LG, Roselli EE, Pettersson G, Johnston DR, Soltesz EG, et al. 14-3-3 in thoracic aortic aneurysms: identification of a novel autoantigen in large vessel Vasculitis. Arthritis Rheumatol. 2015;67(7):1913-21.

87. Kistner A, Bigler MB, Glatz K, Egli SB, Baldin FS, Marquardsen FA, Mehling M, Rentsch KM, Staub D, Aschwanden M, et al. Characteristics of autoantibodies targeting 14-3-3 proteins and their association with clinica features in newly diagnosed giant cell arteritis. Rheumatology (Oxford). 2017:56(5):829-34.

88. Feist E, Kuckelkorn U, Dorner T, Donitz H, Scheffler S, Hiepe F, Kloetzel PM Burmester GR. Autoantibodies in primary Sjogren's syndrome are directed against proteasomal subunits of the alpha and beta type. Arthritis Rheum. 1999;42(4):697-702.

89. Feist E, Dorner T, Kuckelkorn U, Schmidtke G, Micheel B, Hiepe F, Burmester GR, Kloetzel PM. Proteasome alpha-type subunit C9 is a primary target of autoantibodies in sera of patients with myositis and systemic lupus erythematosus. J Exp Med. 1996;184(4):1313-8.

90. Fierabracci A, Saura F. Identification of a common autoantigenic epitope of protein disulfide isomerase, golgin-160 and voltage-gated potassium channel in type 1 diabetes. Diabetes Res Clin Pract. 2010;88(2):e14-6.

91. Weber CK, Haslbeck M, Englbrecht M, Sehnert B, Mielenz D, Graef D, Distler $\mathrm{JH}$, Mueller RB, Burkhardt $\mathrm{H}$, Schett $\mathrm{G}$, et al. Antibodies to the endoplasmic reticulum-resident chaperones calnexin, BiP and Grp94 in patients with rheumatoid arthritis and systemic lupus erythematosus. Rheumatology (Oxford). 2010;49(12):2255-63.

92. Miyachi $K$, Hosaka H, Nakamura N, Miyakawa H, Mimori T, Shibata M, Matsushima S, Chinoh H, Horigome T, Hankins RW, et al. Anti-p97NCP antibodies: an autoantibody marker for a subset of primary biliary cirrhosis patients with milder disease? Scand J Immunol. 2006;63(5):376-82.

93. Kobayashi S, Hiwasa T, Arasawa T, Kagaya A, Ishii S, Shimada H, Ito M, Suzuki M, Kano M, Rahmutulla B, et al. Identification of specific and common diagnostic antibody markers for gastrointestinal cancers by SEREX screening using testis CDNA phage library. Oncotarget. 2018;9(26):18559-69.

94. Liu M, Subramanian V, Christie C, Castro M, Mohanakumar T. Immune responses to self-antigens in asthma patients: clinical and immunopathological implications. Hum Immunol. 2012;73(5):511-6.

95. Papiha SS, Pal B. Gc (vitamin D binding protein) subtypes in rheumatoid arthritis. Hum Genet. 1985;70(3):278-80

96. Van den Bergh K, Vercammen M, Regenass S, Derua R, Vermeersch $P$, Pokreisz P, Ocmant A, de Beeck KO, Janssens S, Waelkens E, et al. Betaine homocysteine methyl transferase 1, a novel auto-antigen associated with anti-Golgi immune reactivity. Clin Chim Acta. 2012;413(1-2):105-8.

97. Vasilev W, Noe R, Dragon-Durey MA, Chauvet S, Lazarov VJ, Deliyska BP, Fremeaux-Bacchi $\vee$, Dimitrov JD, Roumenina LT. Functional characterization of autoantibodies against complement component C3 in patients with lupus nephritis. J Biol Chem. 2015:290(42):25343-55.

98. Arnett FC, Reichlin M. Lupus hepatitis: an under-recognized disease feature associated with autoantibodies to ribosomal P. Am J Med. 1995:99(5):465-72.

99. Yamagiwa S, Kamimura H, Takamura M, Aoyagi Y. Autoantibodies in primary biliary cirrhosis: recent progress in research on the pathogenetic and clinical significance. World J Gastroenterol. 2014;20(10):2606-12.

100. Ehser J, Holdener M, Christen S, Bayer M, Pfeilschifter JM, Hintermann E, Bogdanos D, Christen U. Molecular mimicry rather than identity breaks Tcell tolerance in the CYP2D6 mouse model for human autoimmune hepatitis. J Autoimmun. 2013:42:39-49.

\section{Publisher's Note}

Springer Nature remains neutral with regard to jurisdictional claims in published maps and institutional affiliations. 